\title{
natureouTLOoK AGRICULTURE AND DROUGHT
}

26 September 2013 / Vol 501 / Issue No. 7468

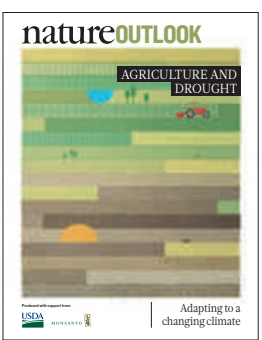

Cover art: Gavin Potenza

Editorial

Herb Brody, Michelle Grayson, Tony Scully,

Nick Haines,

Rebecca Dargie

Art \& Design

Wes Fernandes,

Mohamed Ashour,

Amr Rahma,

Yara Abdel Rahman,

Alisdair Macdonald

Production

Donald McDonald,

Susan Gray, lan Pope,

Leonora Dawson-

Bowling

Sponsorship

Greg Valero, Yvette

Smith, Reya Silao

Marketing

Elena Woodstock,

Steven Hurst

Project Managers

Christian Manco,

Anastasia Panoutsou

Art Director

Kelly Buckheit Krause

Publisher

Richard Hughes

Magazine Editor

Rosie Mestel

Editor-in-Chief

Philip Campbell
$\mathrm{D}$ rought has long been a scourge of humanity and a factor in war and conflict. The current crisis in Syria, for example, comes in the wake of one of its worst ever droughts. Periodic droughts occur because of global temperature cycles in the oceans and atmosphere. But although we understand the causes better, we are still at the mercy of an inherently chaotic weather system.

Add human-induced climate change to the mix and there is an extra incentive to do better. The greenhouse effect is predicted to raise temperatures and prolong droughts (page S2). Many agricultural pests are expected to thrive (S15). All these pressures are putting a squeeze on supplies of fresh water. Farmers need to know how to grow more while using less of this precious commodity (S4).

Research is playing its role. New crop varieties being developed can tolerate higher temperatures and need less water (S7). Computer models that can better predict when and where droughts will hit would help farmers plan - although running these more complicated models is straining computing resources (S10).

Central to long-term food security is implementing a sustainable agricultural system - one that is more resilient and doesn't require continued costly inputs such as synthetic fertilizer and pesticides. Research into the crucial role played by soil microbes provides an insight into how this might be achieved (S18). All this emphasizes the difficulty in tackling this global problem on a local scale: there is no single right answer. Individual farmers need to be empowered to do what is right for their land - a process that can be promoted by smart government policies (S12).

We acknowledge the financial support of the United States Department of Agriculture and Monsanto Company in producing this Outlook. As always, Nature has full responsibility for all editorial content.

Michelle Grayson

Senior editor, Nature Outlook
Nature Outlooks are sponsored supplements that aim to stimulate interest and debate around a subject of interest to the sponsor, while satisfying the editorial values of Nature and our readers' expectations. The boundaries of sponsor involvement are clearly delineated in the Nature Outlook Editorial guidelines available at http://www. nature.com/advertising/resources/pdf/outlook_guidelines.pdf CITING THE OUTLOOK

Cite as a supplement to Nature, for example, Nature Vol XXX, No. XXXX Suppl, Sxx-Sxx (2013). To cite previously published articles from the collection, please use the original citation, which can be found at the start of each article.

VISIT THE OUTLOOK ONLINE

The Nature Outlook Agriculture and Drought supplement can be

found at http://www.nature.com/nature/outlook/agriculture-drought
All featured articles will be freely available for 6 months. SUBSCRIPTIONS AND CUSTOMER SERVICES For UK/Europe (excluding Japan):Nature Publishing Group, Subscriptions, Brunel Road, Basingstoke, Hants, RG21 6XS, UK. Tel: +44 (0) 1256329242 . Subscriptions and customer services for Americas - including Canada, Latin America and the Caribbean: Nature Publishing Group, 75 Varick St, 9th floor, New York, NY 10013-1917, USA. Tel: +1 8663637860 (US/Canada) or +1 212726 9223 (outside US/Canada). Japan/China/Korea:Nature Publishing Group - Asia-Pacific, Chiyoda Building 5-6th Floor, 2-37 Ichigaya Tamachi, Shinjuku-ku, Tokyo, 162-0843, Japan. Tel: +81 332678751. CUSTOMER SERVICES

Feedback@nature.com

Copyright $\odot 2013$ Nature Publishing Group

\section{CONTENTS}

S2 HYDROLOGY

The dry facts

Are droughts getting worse?

S4 WATER

The flow of technology

There are improvements in the pipeline

S7 PLANT BREEDING

Discovery in a dry spell

Advances in the field of crop genetics

S10 MODELLING

Predictive yield

Better weather forecasts would help farmers prepare for drought

S12 PERSPECTIVES

Legislating change

Governments should do more to help manage the risks of drought

S15 CROP PESTS

Under attack

A changing climate increases the threat from insects

S18 MICROBIOME

Soil science comes to life

Fungi and bacteria provide help for stressed plants

\section{COLLECTION}

\$20 Defining the core Arabidopsis thaliana root microbiome

Derek S. Lundberg et al.

\$25 Revealing structure and assembly cues for Arabidopsis root-inhabiting bacterial microbiota

Davide Bulgarelli et al.

\$30 Adaptation of US maize to temperature variations

Ethan E. Butler and Peter Huybers

\$35 Solutions for a cultivated planet Jonathan A. Foley et al.

S4I Little change in global drought over the past 60 years

Justin Sheffield, Eric F. Wood \& Michael L. Roderick 